\title{
Kentler ve Yeni Kentsel Kuramlar: Kentleşmeyi Merkezine Alan Üç Kuram Üzerine
}

\section{Cities and New Urban Theories: On Three Theories That Center Urbanization}

\section{Emine Yetişkul}

Orta Doğu Teknik Üniversitesi, Mimarlık Fakültesi, Şehir ve Bölge Planlama Bölümü, Ankara

ÖZ

Bugün çoğunluğu kentlerde yaşayan nüfusun, yakın gelecekte kentleşme eğiliminin de devam etmesiyle, daha da artacağı kesin olarak beklenmektedir. Geleceğin kentlerinin bugünün kentlerinden farklı olacağı bilinmektedir. Bu noktada kentlere ilişkin araştırmaların önemi de artmaktadır. Bu makalede yakın zamanda öne çıkan üç farklı kentleşme yaklaşımı, Gezegensel Kentleşme, Postkoloniyal Kentleşme ve Birleşmeler Kentleşmesi ele alınacaktır. Farklı kuramsal düşünce temellerine sahip ancak aralarındaki sınır çizgileri keskin olmayan bu üç yaklaşımın ortak özelliği, şehirlere, kentleşmeye ve kentselliğe ilişkin bugüne kadar bilinegelen doğrusalıkları, hiyerarşileri ve sınıflandırmaları eleştirmesidir. Gezegensel Kentleşme kent-kır ikilemini, Postkolonyal Kentleşme Küresel Kuzey-Güney veya Batı-Doğu ikilemini ve Birleşmeler Kentleşmesi de geçmişi-potansiyeli, gerçekleşeni-olasılığı veya sosyal-nesnel olanı sorgulamaktadır. Makalede, bu üç kentsel yaklaşıma yönelik eleştiriler de dikkate alınarak, genel bir değerlendirme yapılmaktadır.

Anahtar sözcükler: Kavramsal olarak kent; kentsel kuramlar; kentleşme yaklaşımları.

\begin{abstract}
Today, the majority of the population living in cities is expected to increase with the continuation of urbanization trend in the near future. It is known that the cities of the future will be different from the cities of today. At this point, the importance of the researches about the cities increases. In this article, three recent urbanization approaches, Planetary Urbanization, Postcolonial Urbanization and Assemblage Urbanization will be discussed. The common feature of these three approaches, which have different theoretical thought bases with no delineating lines among them, is that they criticize the ongoing linearities, hierarchies and classifications of cities on urbanization and urbanity. Planetary and Postcolonial Urbanization question urban-rural dilemma and Global North-South or West-East divide, respectively while Assemblage Urbanization examines past-potential, actual-virtual or social-practical. In the article, a general evaluation is carried out by taking criticisms towards these three urban approaches into consideration.
\end{abstract}

Keywords: City in conceptuality; urban theories; urbanization approaches.
Geliş tarihi: 24.10.2019 Kabul tarihi: 27.08.2020

Online yayımlanma tarihi: I3.10.2020

Iletişim: Emine Yetişkul

e-posta: yetiskul@metu.edu.tr 
Son yıllarda günümüz kentleri ve onlara dair süreçler, temel akademik alanlar yanı sıra yeni ortaya çıkan disiplinler arası alanların da araştırma gündemini belirlemiş ve çekirdeğini oluşturmuştur. Bunun bir nedeni, son otuz yılda kentleşmenin hız, ölçek ve kapsamındaki temel değişim ise, diğer nedeni kentleşme sürecinin artık küresel bir fenomene dönüşmüş olmasıdır (Lefebvre 2003 [1970]; Brenner 2014). Bir yandan 2018 yılında \%55 olan kentsel nüfusun 2050 yılında \%68'e çıkacağı öngörülmekte (UN 20I8), diğer yandan kentsel yaşam biçimleri, kırsal alanlara kadar sirayet etmektedir; kentleşme kırsal alanları da dönüştürmekte, kır-kent ayrımı ortadan kalkmaktadır. Modern kentleşme ve kentsel süreçler akademideki canlılığı uluslararası ilişkilere de taşımıştır. Birleşmiş Milletlerin son dönem birçok sözleşmesi, kent ile çevre arasındaki ilişkilere odaklanmaktadır. Küresel ısınma ile ilgili Viyana Sözleşmesi (1985), Montreal Protokolü (1987), sürdürülebilir kalkınmaya yönelik Yerel Gündem 2 I Eylem Planı, küresel iklim değişikliğine karşı Kyoto Protokolü (1997), Kopenhag Uzlaşması (2009) ve Paris Anlaşması (20I5) gibi örnekler günümüz kentleri ve kentsel süreçleri inkar edilemez düzeyde uluslararası ilişkilerin gündemine taşımıştır.' 2016 yılında Quito'da gerçekleştirilen Habitat IIl'ün sonuç bildirgesi olan "Yeni Kentsel Gündem” incelendiğinde, son dönem kentleşme ve kentsel süreçlerin artık gezegenin temel konuları arasına girdiği ileri sürülebilir (UN 2016).

Kentler ve kentsel süreçler sadece uluslararası gündeme değil ulusal gündeme de etki etmektedir. Politikacılar ve plancılar, kentlerin gelişimi ve dönüşümü üzerinden sürekli yeni planlama ve yönetişim yaklaşımları önermekte, kentlerin karmaşık yapısını yönetmek için yeni uygulama araçları üzerine mesai vermektedir. Her ne kadar hem akademik hem de politika odaklı çevrelerde kapsamlı araştırmalar yapılmış, zengin tartışmalar ortaya çıkmış olsa da kentleri, kentleşmeyi ve kentselliği tam olarak açıklayabildiğimiz söylenemez. 2009 yılında gerçekleştirilen Kentleşme Şurası bu konuda iyi bir örnektir (BiB 2009). Çevre ve Şehircilik Bakanlığı'nca düzenlenen şuranın içerdiği akademik çeşitliliğe, odak grupların detaylı çalışmalarına ve tartışma süreçlerinin derinliğine rağmen günümüzün kentlerine, mekandan bağımsızlaşan kentleşmeye ve küresel ölçekte kentselliğe yönelik öneriler kısıtlı kalmıştır. Üstüne üstelik ne kent üzerine uzlaşılan bir tanım veya form ne de kentleşme veya kentsellik üzerinde uzlaşılan yaklaşım da bulunmamaktadır.
İdeal kent arayışları tarihsel olarak antik çağlara kadar uzansa da kentle ilgili sistematik akademik çabalar, 1920'lerde ve 1930'larda Şikago Okulu'nun kentsel ve ekolojik sistemler arasındaki benzerlikleri ortaya koymaları ile başlamıştır. ${ }^{2-4}$ Park, Burgess ve Wirth gibi bilim insanları ekolojik sistemlerden çıkarımlar (analoji) yaparak kenti tanımlamaya çalışmışlardır. Wirth (1938, s.8), şehri 'büyük, yoğun ve sosyal açıdan farklı bireylerin kalıcı olarak yaşadıkları yer' olarak tanımlamıştır. Elbette bu, herkesin üzerinde oydaşacağı bir tanım olabilir. Kent, özellikle de metropoliten kentler, endüstriyel, ticari, finansal ve idari birçok faaliyetin yoğunlaşmasını içerir. Tiyatroları, kütüphaneleri, müzeleri, konser salonları, operaları, hastaneleri, okulları, araştırma merkezleri, yayın evleri, meslek örgütleri, dini ve sosyal kurumları bir arada barındırır. Wirth'in tanımındaki "büyüklük" ve "yoğunluk" temel değişkenler olsa da kentteki farklılıkları ekonominin işleyişi ile açıklamıştır. Bireylerin kentte bir araya gelme sebebini, her bireyin bir diğeri için sunduğu faydada görmüştür. Dolayısıyla kentteki farklılıklar, "büyük” ve "yoğun” kentin isteklerine göre şekillenmekte, bireylerin özgürlük ve bireyselliklerini ifade etmemektedir.

1960'lardan itibaren kente dair çeşitli ve farklı zengin tartışmalar dönemine girilmiştir. Jacobs (196I) kentlerdeki farklılıkları, Wirth'in tersine, çeşitlilik olarak yorumlamıştır; her çeşit fikir ile girişimciliği destekleyen kenti, kendi kendine bir düzen oluşturan sistem olarak tanımlamıştır. Görünür bir kaos ortamından kozmosun ortaya çıktığını vurgularken, “kentsel karmaşıklığın” ve "çeşitliliğin” dinamizmi ve yaratıcılığı tetikleyerek düzeni yarattığını öne sürmüştür. İlginç bir şekilde Jacobs'un bu ufuk açıcı görüşü, bugünkü karmaşıklık ve kaos kuramlarından etkilenen, kentleri, dinamik, doğrusal olmayan, sürekli değişen ve kendini uyumlandıran karmaşık sistemler olarak gören yeni yaklaşımın ipuçlarını da içermektedir (Yetişkul 2017).

1960'ların sonunda yazan Lefebvre (1991 [1974]) mekanın üç boyutunu- algılanan (perceived), tasarlanan (conceived) ve yaşanan (lived)- olarak tanımlamıştır; ancak Lefebvre'in asıl ilgisi, 'mekandaki şeyler' değil, gerçek mekanın üretimidir (Arslan Avar 2009). 'Mekanın üretimi' ise toplumsal bağlamı ve üretim süreçlerini işaret etmektedir. Bu mekan kuramı aynı zamanda Marksist bir mekan-politik projedir: 'Dün-

\footnotetext{
Örneğin, Sancar (2017) Türkiye'de kentleşme çevre sorunları arasındaki ilişkiyi küresel ölçekteki eylemler ışığında incelemektedir.

2 Kentsel kuramları tartışmak üzere derlenen güncel uluslararası kitaplarda ve makalelerde Şikago Okulu özellikle kentsel (the urban) ile ilgili en koordine akademik çaba olarak görülmektedir (Bknz. Jayne ve Ward (2017) Urban Theory New Critical Perspectives; lossifova vd. (20I8) Defining the Urban Interdisiplinary and Professional Perspective; ve Scott ve Storper (20I5) The Nature of Cities: The Scope and Limits of Urban Theory (2014). Bu doğrultuda yazıya Şikago Okulu'nun tanımlamaları ile başlanılmıştır.

3 1920'lerden önceki dönem sanayileşmenin gerçekliği karşısında şehirdeki değişiklikleri araştırmaya yönelik gelişmiştir. Friedrich Engels (I820-ı895) sanayi devrimini 'aynı zamanda sivil toplumun tamamını değiştiren bir devrim' olarak açıklamıştır. Karl Marx şehri bir sorgulama nesnesi olarak ele almasa da Das Capital [ı67] kitabında '(a) belirli bir gelişme derecesine ulaşan ve (b) malların değiş tokuşuna neden olan her işbölümünün temelinde kentin kırdan ayrılması’ olduğunu söylemiştir (Marx 1976, s.46I). Engels The Conditions of the Working Class in England (1845) adlı kitabında kapitalist sanayi kentinin acımasız etkilerini anlatmıştır. Buradaki sorun kent ile ilgili veya kentsel değildir; kapitalist üretim tarzıdır. Sanayi kentindeki durumu ve koşulları hızla değiştiren kapitalizmdir. Mülk sahipliği ile fabrika üretimine ve bunların tüm çelişkilerine dayanan toplumda sermaye birikimini sağlamak için insan eli ile yapılan şey, Engels'in kentidir (Schlichtman, 2018).

4 Max Weber (1864-1920), The City kitabında şehri, tarım ilişkilerine değil en temelde alışveriş ve ticaret ilişkilerine dayanan bir yer olarak tanımlamıştır. 'Sadece yerel halkın yerel pazarda günlük ihtiyaçlarının ekonomik olarak önemli bir kısmını karşıladığı durumlarda' şehirden bahsedebileceğimizi söylemiştir (Weber 1958, s.66-67). Dahası, şehrin bir mahkemesi ile bir kanunu olduğunu ve bir dereceye kadar da siyasi özerkliğinin bulunduğunu eklemiştir. Şehir hayatında dernekler ve örgütler de olduğu için sosyal katılımın varlığından da söz etmiştir (Schlichtman, 2018).
} 
yayı değiştirmek için, mekanı değiştirmek gerekmektedir' (Lefebvre 199I [1974]; Schmid 2008). ${ }^{5}$ Marksist akademisyenler şehirde ortaya çıkan gerilim ve çatışmaları kapitalist toplum ve özellikle kapitalist devlet üzerinden yorumlamışlardır. Burada kentlerin sanayi birikimi için en uygun yerler olarak üretilmesi ve işçi sınıfının kapitalizmde toplumsal yeniden üretimi, asıl endişeleridir (Jonas vd. 2018). Bu sonuca özellikle 1970'lerin sonunda Manuel Castells ulaşmıştır. Kent ve kentselliğin kapitalist sanayileşmeyle bağlantılı sosyal örgütlenme biçimi olduğunu; ve aslında tarihsel bir gerçekliğe dayandığını belirtmiştir (Castells 1977, s.8I). Şehrin kendi başına açıklanabileceği veya bağımsız bir değişken olabileceği fikrini redederek kente ilişkin sorunların, toplumun bizatihi kendi sorunları olduğunu vurgulamış ve tartışmaları 'kentin ötesine' taşımıştır (Castells 1978).

David Harvey, şehri 'çevresinde belirli bir üretim biçiminin devam ettiği bir eksen' olarak açıklamıştır (Harvey 1973, s.202). Kapitalist şehir, 'mekanın bir meta olarak alınıp satılması' ile ortaya çıkan arazi rantı üzerinden oluşmaktadır. Bu da mekanın homojen, evrensel, nesnel ve soyut olarak pekiştirilmesiyle sağlanmaktadır (Harvey 1985, s. I3). Kentleşmenin, kapitalizme özgü sosyal ilişkiler yoluyla üretilen bir süreç olduğu ve kentlerin mevcut eşitsizlikleri arttıran sermaye birikiminin sonucu ortaya çıktığını vurgulamıştır (Harvey 1989; Harvey 1996). Aslında 'şehir' dediğimiz 'şey'in kentleşme dediğimiz bir sürecin ara kesiti olduğunu öne sürmüştür (Brenner 2014, s.6I).

Kentlere ilişkin çalışmalar giderek çoğalmış ve 1980'lerde tartışmalar, kentin içindeki sorunlara kaymıştır. Kentsel yoksulluk, gecekondular, eski sanayi alanları, konuta erişim, sosyal ayrışma, çöküntü alanları, koruma, soylulaştırma, kentsel suç, ekolojik ve iklimsel mücadele gibi konulara odaklanılmıştır. Bu noktada kente ait veya kentin olanlarla, kentte olanları birbirinden ayırmanın önemine dikkat çekilmiştir (Storper ve Scott, 2016). Nitekim kentlerin neden ortaya çıktığını veya nasıl işlediğini sormak, kentsel bir ortamda oluşmuş olanları sorgulamaktan farklıdır. Biri diğerinden daha önemli değildir, ancak tartışmalara bu açıdan yaklaşmak önemlidir. Örneğin, kentlerin neden ortaya çıktığını ve neden büyüdüğünü, Scott ve Storper (2015) yığılma süreçleriyle açıklamıştır. Her ne kadar farklı konumlarda yer alsa da sadece ekonomik faaliyetlerin değil sosyal faaliyetlerin de kentlerde yoğunlaştığını; ve bu yığılmanın ekonomik kalkınmayı sağlarken toplumu da bir bütün olarak etkilediğini ve geri beslediğini eklemiştir. Öte yandan kentleşme süreçlerinin ve kentselliğin kentleri aştığını, artık fiziksel bir formu tanımlamanın veya kent nedir sorusunu cevaplandırmanın anlamsızlaştırdığını dile getiren kimi yaklaşımlar, temeline ekonomiyi koyan açıklamaları eleştirilmektedir (Örneğin: Brenner, 2014).

Görülüyor ki kapsamlı ve bir o kadar da zengin bir akademik yazın oluşmuştur. Bu yazını, ampirik ve analitik olanlar ile yorumlamacı ve eleştirel olanlar diye genel olarak ikiye gruplandırabiliriz. Ampirik ve analitik yaklaşımlar, teknolojik ve bilişsel ilerlemelerden de faydalanarak son dönemde gelişkin kent modelleri kurgulamış ve yeni ortaya çıkan büyük veri setleriyle tartışılagelmekte olan kuramları irdelemiştir. Özellikle hücresel özişleme (cellular automata) ve temsilci-tabanlı (agentbased) modeller, şehirleri karmaşık sistemler olarak simüle etmek için ana araç haline gelmiştir (Batty ve Longley 1994; Portugali 2000; Benenson ve Torrens 2004; Silva ve Clarke 2005) ve geleneksel niceliksel kent modellerinden güç yasası dağılımlarını modelleyen çalışmalar da yaygınlaşmıştır (Bknz. Yetişkul, 2017). Bu yaklaşımda kentler, karmaşık ve kendi kendini örgütleyen sistemlerdir. Bu modeller zaman-mekanda hareket eden bir çok temsilcinin arasındaki etkileşimden sadece kentlerin değişimini veya gelişimini değil bu sistemlerinin iç oluşlu yani endojen bir şekilde evrildiğini ve içten bir komutla nasıl ortaya çıktıklarını da açıklamaktadır.

Bu ampirik ve analitik yaklaşımlar, kabul görmüş bulguların veya geçerli söylemlerin hızla sorgulanmasına ve tüketilmesine neden olmuş, ikinci grup altında gelişen yeni yorumların ve eleştirel yaklaşımların ortaya çıkışını da desteklemiştir. Söz konusu kentler, kentleşme ve kentsellik olunca, bütünleştirici bir kuram geliştirmek, kentsel araştırmalara ortak bir dil tanımlamak ya da kimi iddialı arayışları eleştirmek için yeni yaklaşımlar ortaya atılmıştır. Bu makale yakın zamanda ortaya çıkan bu yaklaşımlar arasından öne çıkan üçünü incelemektedir. $\mathrm{Bu}$ yeni yaklaşımlar Gezegensel Kentleşme (Planetary Urbanization), Postkoloniyal Kentleşme (Postcolonial Urbanization) ve Birleşmeler Kentleşmesi (Assemblage Urbanism) ele alınacaktır. Farklı düşünce temellerine sahip ancak aralarındaki sınır çizgileri keskin olmayan bu üç yaklaşım aşağıda açıklanmaya çalışılacak, yaklaşımlara yönelik eleştiriler de dikkate alınarak genel bir değerlendirme yapılacaktır.

\section{Gezegensel Kentleşme}

Gezegensel Kentleşme'nin teorik arka planı geleneksel Avrupa kentlerinin çözülmesine, Paris, Ruhr Havzası ve İskandinavya'ya uzanan büyük çaplı bölgesel metropolisin ortaya çıkışına dayanmaktadır. Kentleşmenin bölgesel ve kıtasal ölçeği aştığını ve ‘kentsel doku'nun (Lefebvre, 2003 [1970]) gezegeni sardığını belirten Brenner ve Schmid (20।4), okyanuslardan atmosfere yeryüzündeki her şeyin neoliberalizmin, küresel kapitalizmin ve ekonomik büyümenin aracı olduğunu

\footnotetext{
5 Lefebvre'nin The Right to the City [1968], The Urban Revolution [1970] ve The Production of Space [1974] günümüze kadar kentsel yazını etkilemiştir. Argümanlarını Manuel Castells The Urban Question [1972] başlıklı eserinde kapsamlı bir şekilde değerlendirmiştir. David Harvey'nin Social Justice and the City [1973] kitabı da The Urban Revolution ile benzerlikler göstermektedir; ancak Harvey kitabının sonuç bölümünde Lefebvre'nin kitabını henüz çalışmadığını açıklamıştır (Schlichtman, 20।8, s.22). Lefebvre eleştirel kentsel kuramcilara ilham vermeye devam etmektedir.
} 

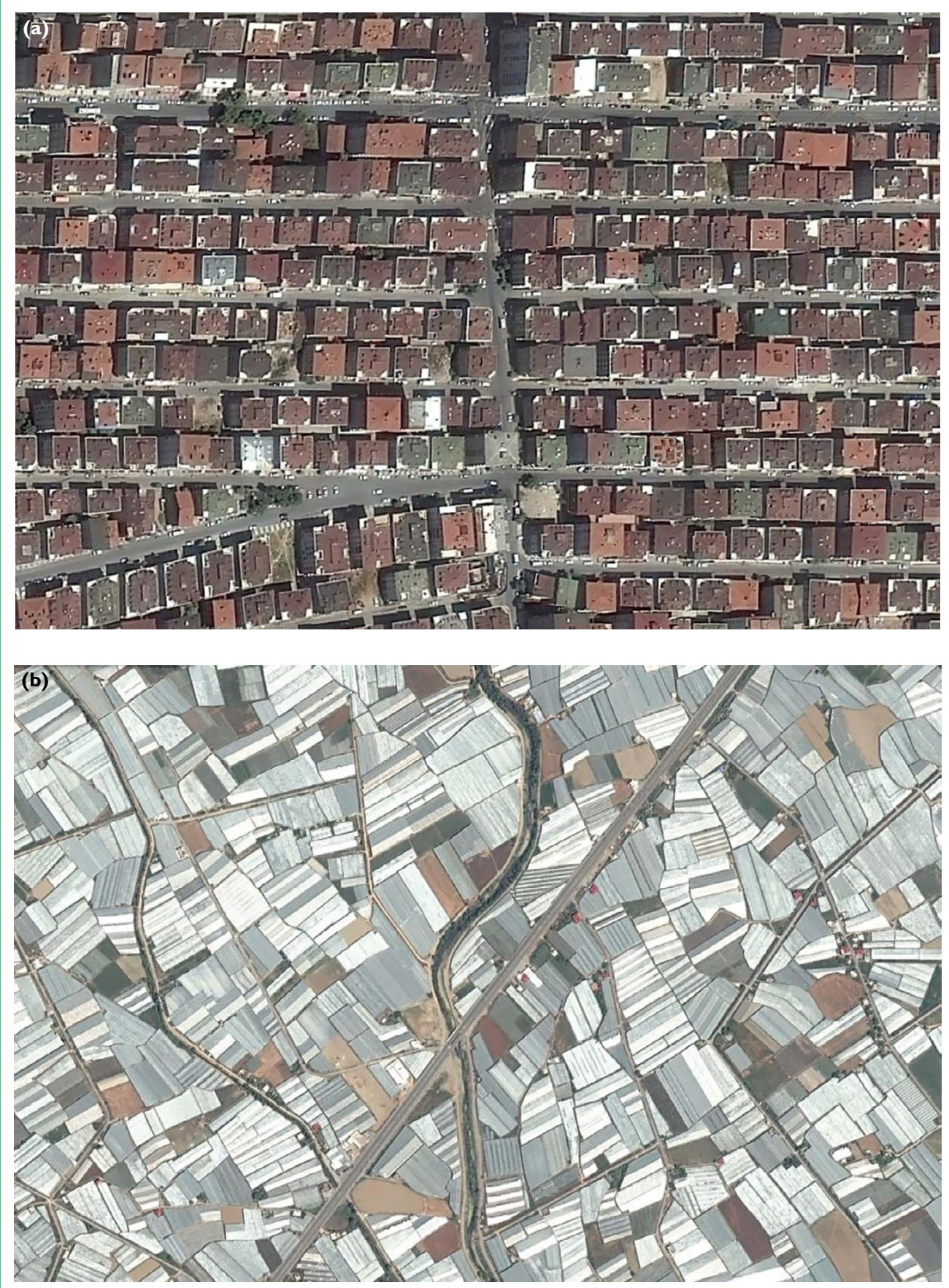

Şekil I. (a) Kent dokusu (Maltepe, İstanbul). (b) Kır dokusu (Anamur, Mersin) (Yandex, 2019).

ve işlevselleştirildiğini savunmaktadır (Şekil I). Ilginç bir şekilde, kentleşmenin sadece kentsel ortamları değil, aynı zamanda kentlerin hinterlandı olan kırsal alanları da etkilediği ve belirlediğini Davis (1955, s.429) yıllar önce vurgulamıştır. Gesellschaft
(Türkçe: cemiyet) ne kadar yaygınlaşırsa veya genelleşirse tüm dünyanın bir büyük şehre benzemeye başlayacağını Tönnies, 19.YY'ın sonunda ileri sürmüştür. ${ }^{6}$ Bugün insan ve çevre ilişkilerini anlamamız ve dolayısıyla yorumlamamız da değişmiştir.

6 1920'lerden önceki döneme dahil edebileceğimiz Ferdinand Tönnies (1855-1936) de şehri, tehlikeli bir evrim sürecinin bir anı olarak açıklamıştır ve şehirdeki sosyal yapının acımasızca insanlık-dışı yollarla şekillendiğini söylemiştir. Gemeinschaft ve Gesellschaft [1887] adlı kitabında cemaat (gemeinschaft) toplum (gesellschaft) ayrımı üzerinden iki farklı kurumu açıklamıştır. Tönnies'e benzer şekilde Emile Durkheim (I858-1917), Toplumdaki Emek Bölümü [1893] adlı kitabında iki tür sosyal dayanışmayı açıklamıştır. Mekanik dayanışma, Tönnies'in gemeinschaft kavramındaki gibi inanç, gelenek, din, dil ve dünya görüşünün benzerliğine dayanan sosyal bağları anlatırken organik dayanışma ise toplumsal farklııılara ve toplumun işbölümünde rollerin uzmanlaşması nedeniyle gelişen karşılıklı bağımlılı̆̆ı vurgulamaktadır. Durkheim doğrudan şehirleri incelemese de bu tür rollerin sosyal olduğunu belirtmiştir (Schlichtman, 2018). 
Brenner (20I4) kentleşme süreçlerinin şehrin sınırlarını da ihlal ederek çevresel süreçlere nüfus ettiğini ve iç içe geçtiğini vurgulamaktadır ki kitabının kapak resmi bir megakent değil devasa bir açık maden ocağıdır (Miller ve Jones 2018). ${ }^{7}$

Şehirlerin en belirleyici özelliği olarak görülen kümelenmeyi (agglomeration), endüstrileşmiş kentsel dokunun üretimi ve sürekli dönüşümünü açıklamak için yeterli bulmayan Brenner ve Schmid (20।4), sadece kümelenme odaklarının değil onların işlevsel doğal çevrelerinin de kent dokusunu oluşturduğunu ve birlikte kapitalist sisteme eklemlendiklerini savunmaktadır. Buna ek olarak, şehrin merkezi bir noktadan veya çekirdekten nasıl büyüdüğünü açıklamaya çalışmak yerine, kentsel toplumun oluşumuna, daha doğrusu kentselliğin bir yaşam biçimine dönüşmesine odaklamamız gerektiğini ileri sürmektedir. Belki de kent 'sınırlı, noktasal ve kapalı bir sosyo-mekansal durum' değil 'alansal olarak çeşitli, morfolojik olarak değişken, çokölçekli ve süreçsel' bir yerdir (s.l2). Belki de kent, kentleşmenin ürettiği ve kentleşmeyi üreten bir döngüsel süreçtir; o zaman kentleşme, kenti aşan ve ötesini de içeren bir şeydir. Bu, aynı zamanda, Lefebvre'nin (2003 [1970]) ileri sürdüğü 'kentsel devrim' düşüncesi ve 'toplumun bir bütün halinde kentleşmesi' durumu ile de yakından ilişkilidir. Şehirlerden farklı olarak 'kent toplumu'nun araştırılmasına ilişkin çağrıda bulunan Lefebvre'nin gezegensel kentleşme öngörüsü Brenner (20।4) ve diğerlerine göre artık gerçektir.

Bu bakış açısı, şehir tanımını, mevcut kentleşme süreçlerini anlamak için giderek daha etkisiz hale getirmektedir. Merrifield (20I3) kentin net bir formunun ve kesin çizgilerle belirlenmiş sınırlarının olmadığını belirtmektedir. Çünkü kentin sınırları içinde mi veya dışında mı olduğunu söyleyemediğimiz ilişkiler, eğilimler ve çelişkiler sürekli ortaya çıkmaktadır. Brenner (20।4) şehir kavramını özellikle kullanmamış ve kentsel/kentsel-olmayan gibi bir ikili ile de kentselliği tanımlamaya meyletmemiştir. Bunun yerine kentleşmenin tek tip ve eşitsizlikler yaratan süreç içinde birbirine dolanmış ve birbirini oluşturan çeşitli biçimlerinin (yoğunlaşmış/derişik, genişlemiş/yayılmış veya ayrışmış) ortaya çıktığını vurgulamıştır. Buna ek olarak Angelo ve Wachsmuth (2014) kentleşmenin farklı coğrafyalarda ve çeşitli coğrafi ölçeklerde de ortaya çıktığını belirtmiştir.

Bu yapısalcı yaklaşım bir taraftan yoğun bir şekilde tartışılmakta ve benimsenmekte iken diğer bir taraftan da eleştirilmektedir. Walker (20I5 s. 186) kentselliğin kırsal alanlar dahil her şeyi kapsayacak şekilde genişletilmesinin ve her şeyin kentleşme ile açıklanmasının tehlikeli olabileceğini belirtmiştir. Şehri kırdan ayırt etmek kadar kentseli ve kırsalı kavramsallaştırmak da gittikçe zorlaşmıştır. Her şeyi kentleştirmenin doğru olmadı̆̆ını belirten Shin (20I8), kent dışı süreçlerin, kentsel güçler tarafından teslim alınan değil, mutasyon yoluyla varlıklarını devam ettirebilen süreçler olarak ele alınması gerektiğini belirtmiştir. Kuramdan yola çıkarak kentlere yönelik politika ve uygulama araçları geliştirmek de önemlidir ki gezegensel kentleşmenin bu konuda ikna ediciliği görece yetersiz görülmüştür (Cochrane 20/8). Bu eleştirilerden ortaya çıkan, kentin, kentselliğin ve kentleşmenin maddeleştirilmiş olmasıdır.

\section{Postkolonyal Kentleşme}

Postkolonyal düşünce, sömürgeciliğin düşünsel mirasının Küresel Güney hakkındaki bilimsel yazılara bilinçsizce girdiğini gösteren çalışmalardan (Örneğin; Said 1978) etkilenerek gelişmiştir.' Avro-Amerikan teorisinin kendi başına savunduğu evrensellik iddialarının yanlış olduğu Comaroff ve Comaroff (20I2) gibi eleştirel çalışmalarda da ortaya konmuştur. Bu düşünce ve eleştiri çizgileri son dönem kent çalışmalarında da etkili olmuştur (Robinson 2006 ve Roy 2009). Kentleşme dünya çapında bir süreçtir. Ancak bu temel bir kentsel formun evrenselleştirilmesi anlamına gelmemelidir (Roy 2016, s.204). Postkolonyal kentleşme, küresel ölçeğin en üstünde yer alan bir kaç seçilmiş kent özelinde geliştirilen kent kuramlarını sorgulayarak özellikle modernizm ve kalkınmacılığı, Küresel Güney'in şehirlerini (ve toplumlarını) azgelişmişlik ve geri kalmışlık statüsüne mahkum ettiği için eleştirmektedir.

Postkolonyal kentleşme için diğer önemli çıkış noktası, Amin ve Graham (1997) tarafından geliştirilen 'sıradan şehir' kavramında yatmaktadır. Şehirlerin eşit derecede farklı ve benzersiz olduğunu ve hiçbirinin diğerlerine ayrıcalıklı bir şekilde model olamayacağı veya örnek teşkil edemeyeceği düşüncesi bulunmaktadır. Postkoloniyal kentleşme, farklı kentlerde çeşitli kentsel süreçlerin paralel bir şekilde deneyimlendiğini kabul etmektedir (Şekil 2). Bu doğrultuda farklı coğrafya ile mekansal bağlamların incelenmesi gerektiğini savunmaktadır. Örneğin, Roy (2005) güney şehirlerindeki yoksulluk, kayıt dışılık, marjinalleşme ve geniş gecekondu bölgelerini bir kentleşme biçimi olarak görmektedir. Ernstson (20l4) bu çoğulculuğu veya çok türlülüğü kentleşmenin ortaya çıkardığı kültürel ve çevresel çeşitlilik olarak açıklamaktadır. Bu, Young'ın deyimiyle: Dünyayı tersine

7 Brenner'in Implosions/Explosions: Towards a Study of Planetary Urbanization adlı kitabıdır.

8 Weber Theory of the Location of Industries (1929) başlıklı çalışmasında sanayi yerseçimi optimizasyonu için kuruluş yeri üçgenini geliştirirken mekansal kümelenmeyi keşfetmiştir. Mumford (1938), şehirleri güç ve kültürün yoğunlaşma noktaları olarak açıklayarak şehirlerin en eski tanımlarından birini kümelenme ile sunmuştur. Kentselliğin ve kentleşmenin de kümelenme süreciyle açıklanabileceğini Storper ve Scott (20I6) savunmuştur. Kümelenmenin sadece ekonomik büyüme üzerinde değil, bir bütün olarak toplum üzerinde de güçlü geri bildirim etkileri olduğunu ileri sürmüştür. 'Kentsel arazi bağları (urban land nexus)' tanımıyla şehir içi mekanının temel dokusu olan arazi kullanımlarının, şehrin ekonomik ve sosyal faaliyetlerinin bir mozaiğe dönüşmesinin yolu olduğunu vurgulamıştır (Scott ve Storper 20।5, s.8).

9 'Post' ön eki en basit anlamıyla sona eren bir durumu ve sonrasını ifade etmek amacıyla kullanılır. Post-kolonyalizm kavramı da esas itibariyle sömürgelerin bağımsızlıkların kazandıkları, kolonyalizm sonrası döneme ilişkindir. Her ne kadar sömürgeciliğin ortadan kalktığını ifade etse de, biraz da ironi içererek, sömürgecilik olgusunun tüm araçlarıyla birlikte ortadan kalkmadığını ve eski sömürge ülkeler için sadece bir yanılsama olduğunu veya 'yeni-sömürgecilik' ya da 'iktisadi-sömürgecilik' gibi adlar altında devam ettiği söylemektedir. Bu açıklama Eyrice Tepeciklioğlu'ndan (20I3 s.9l) aktarılmıştır. Ancak genellikle tire(-) işareti ile ayrılmayan postkolonyalizm ise biraz farklı bir anlam içermekte ve kurama yönelik kullanılmaktadır. 

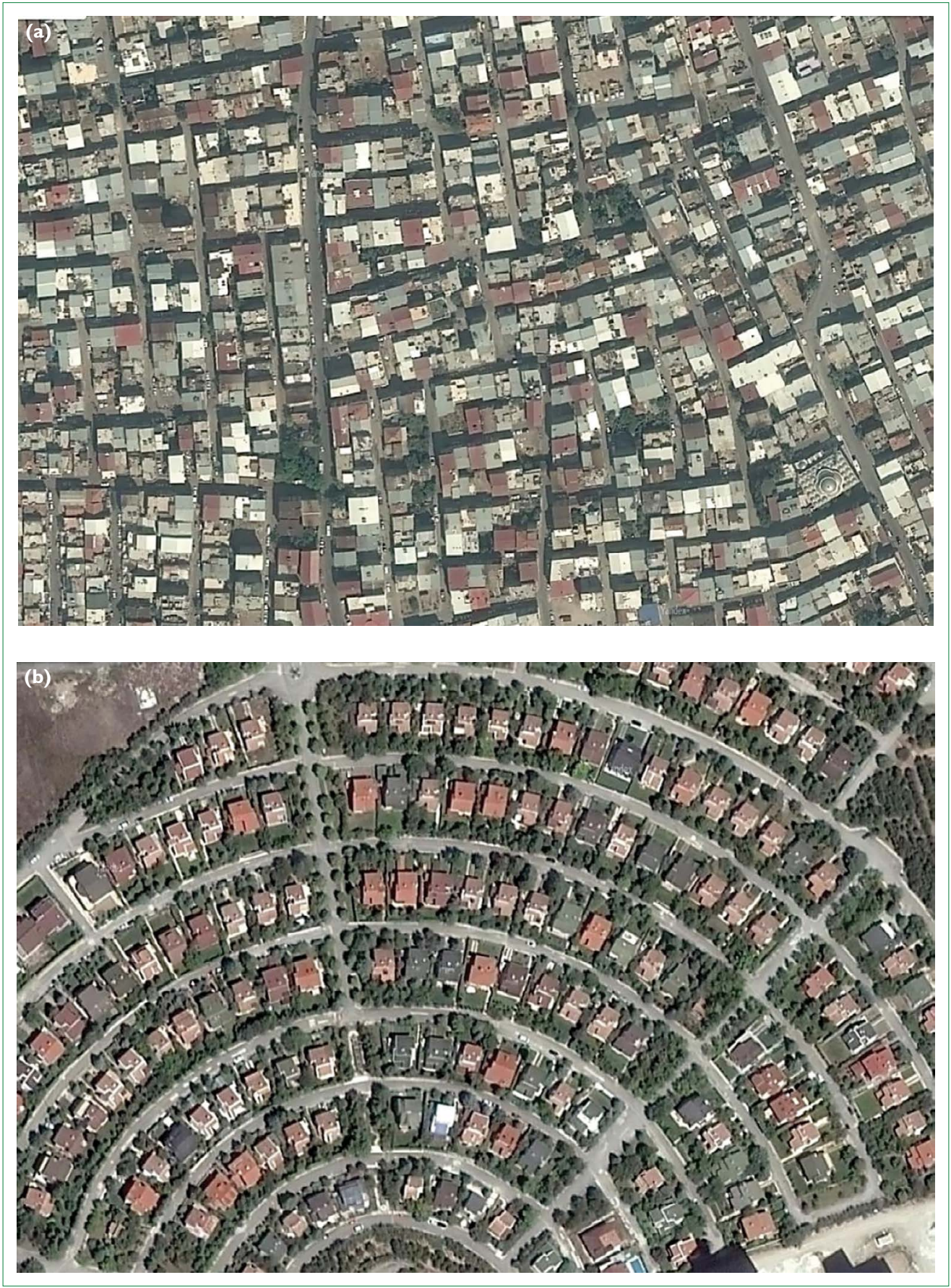

Şekil 2. (a) Küresel Güney’i örnekleyen kentsel form (Buca, İzmir). (b) Küresel Kuzey’i örnekleyen kentsel form (Alacatlı, Ankara) (Yandex, 2019).

çevirmek ve resmin 'öteki' yüzüne bakmaktır; Berlin veya Boston yerine Bağdat'ta veya Benin'de yaşamanın sonucunda bazı şeylerin nasıl farklı görüneceğini ve bunun nedenlerini anlatmaktır (Young 2003). Böylelikle tek-odaklı ve hegemonik/baskın kavramsallaştırmalar ve söylemlerden uzaklaşılacaktır.

Küresel Güney'deki kentlerde deneyimlenen sosyal, ekonomik ve politik uzlaşma ve çatışmaların ürettiği mekansal biçimlerin değerlendirilmesi, alternatif modelleri, politika ve stratejileri ortaya çıkaran örnekleri gözden kaçırmamak açısından da önemlidir (Robinson ve Roy 2016). Ancak, bu mekansal biçimler ve süreçler Batı'da üretilen kavramlarla yorumlanmamalıdır. Yine Young'in deyimiyle: Batılıların, Batıll-olmayan dünyaya baktı̆̆ında gördükleri şey, gerçeğin kendisinden ziyade, aslında aynadaki kendi yansımaları ve kendi varsayımlarıdır (Young 2003, s.2). Her yerde ve her zaman aynı tür kentsel dene- 
yim ortaya çıkmayabilir. Bu noktada da ne kentleri açıklamak için yığılma ekonomileri yeterli olacak, ne de evrensel tek bir kentleşme süreci tanımlanabilecektir.

Büyük kuramlardan uzaklaşarak deneyimlerdeki farklılıkları vurgulamayı öne çıkaran postmodernizm düşüncesinden etkilenen postkolonyal kentleşme, şehirleri günlük yaşamın bir mekanı olarak incelemeyi tercih etmektedir. Günlük yaşam vurgusuyla Lefebvre'ye dayanan postkolonyal düşüncenin kenti son derece politik ve güç ilişkilerinin merkezi olarak kabul ettiği düşünülebilir (Zimmer vd. 2018). Buna karşın, postkolonyal düşüncenin, coğrafı bağlamın ortaya çıkardığı farklılığa dayanarak bugüne kadar üretilen kavram veya kuramları sorgulamasının ne derece gerekli olduğu ve her düşüncenin 'kırsallaştırılması' çabasının arkasındaki nedenler anlaşılamamaktadır. Storper ve Scott (2016) bilgiyi kırsallaştırma ısrarına ek olarak postkolonyal kentleşmeyi karşılaştırmaya ve farklılıklara çok odaklandığı; ve tüm şehirleri etkileyen güçleri gözden kaçırarak parçacılığa saplandığı için eleştirmektedir. Kırsallaştırma örneklerinin Batı düşünce biçiminden öteye geçemeyeceği de iddia edilmektedir.

\section{Birleşmeler Kentleşmesi}

Son yıllarda Birleşmeler Kuramı, sosyal bilimler genelinde olduğu gibi, kent çalışmalarında da önemli bir yaklaşım olarak karşımıza çıkmaktadır. Postkolonyal Kentleşme ile benzerlikleri olan bu kuram, post-yapısalcı düşünürlerin, özellikle Deleuze ve Guattari'nin çalışmalarından yorumlanarak geliştirilmiştir. Felsefi açıdan oldukça karmaşıktır. Deleuze ve Guattari tarafından ortaya atılan 'agencement', bir araya getirme, birleştirme, oluşturma, asemblaj gibi anlamları içermektedir (Deleuze ve Guattari 1987 [1980]). Burada, türdeş olmayan parçaların farklılıklarını koruyarak bir araya gelmesi ve bir bütünü oluşturması önemlidir (Şekil 3). Benzer bir şekilde kentler de insanların, kurumların, ağların, örgütlenmelerin, farklı altyapı ve üstyapı öğelerinin bir araya gelmesinden ve bir arada çalışmasından oluşmaktadır.

Karmaşıklık ve kaos kuramlarından etkilenen Birleşmeler Kuramı, McFarlane'nın söylediği gibi, şimdiki zaman ve mekanda algıladığımız her şeyin hem bir geçmişinin olduğunu, hem de gelecek için bir olasılık oluşturduğunu vurgular (McFarlane 20II). Dolayısıyla, anın gerçekliği, aslında bir son ürün veya sonuç değil, bir akışkanlık halidir. Bu yaklaşım kentleri, sabit, değişmez, sınırları belirgin bir yapı olarak değil, parçaların bir araya gelerek etkileştiği ve sürekli dönüştüğü bir sistem olarak görmemizi sağlamıştır. Bu arka plana dayanarak Farias, kentleri, süreçlerin çeşitliliği olarak tanımlamıştır (Farías 20 I I).

Birleşmeler Kuramı, Avrupa kenti, Amerikan uydu kentleri, Bahçe Kent, Ortaçağ kenti gibi tek tip bir anlatım kavramsallaştırması (DeLanda 2002) yerine oluşumların süreçlerini anlamamız için evrimi içeren ve çeşitliliği gösteren bir şekilde bireyler, sosyal gruplar, örgütler, kentler, nesneler, teknoloji gibi kavramsallaştırmanın yapılmasını önermektedir. Kente binlerce rizomik ağın oluşturduğu karmaşık bir sistem olarak yaklaşan kuramcılar, kentin sosyal ve maddi unsurlarını birleştirerek kenti araştırmaktadır (DeLanda 2002). Bu bağlamda nesneleri de sosyal yapının birer parçası olarak kabul eden Aktör-Ağ Kuramının ve araştırma yönteminin (Latour 2005) ilerisine gitmektedir. Sadece kentteki insanlar değil, insan eliyle yapılmış her şey, kentsel sonuçların şekillenmesinde eşit derecede aktif katılımcılar olarak görülmektedir.

Birleştirme yaklaşımında, bireylerin, olayların ve durumların bir araya gelişi kavranılmaktadır. Birleşmeler Kuramına karşı en temel eleştiri, bütünü oluşturan parçaların varoluşsal temeline inilmemesi de bu noktada ortaya çıkmaktadır. Postkolonyal Kentleşme de benzer bir şekilde eleştirilmiştir. Sosyal hareketler, kurumsal örgütlenmeler veya sosyal ağlar gibi ara düzeyler incelenmemektedir. Daha doğrusu bugüne kadar kente ilişkin pek çok çalışmada yer alan veya sosyal kuramlarda tartışılagelenlerin bir düzeye (mikro veya makro) indirgenmesi basitleştirme olarak görülmektedir. Bunu aşmak için DeLanda bütünden veya parçalardan kurtulmayı önermiştir (DeLanda 2006). Parçalar arasında ne tür nedensellik ilişkileri olduğunu ve farklı bağlamlarda nelerin değişebileceğini açıklamadan 'modern planlama' veya 'kentsel yönetişim' gibi belirlenmiş sistemlere nedenler sunmanın aslında bir basitleştirme olduğunu söylemiştir.

Birleşmeler Kuramı, sosyal bilimlerdeki pek çok geleneksel yaklaşımla karmaşıklık ve kaos kuramları arasındaki bağlantıyı sağlamada önemli olsa da (Wezemael 2010) planlama alanında henüz uygulamadan uzak görünmektedir. Ancak plancılar bu düşünce biçimiyle kentleri daha iyi anlamaya odaklanabilir. Yetişkul ve Demirel (2018) soylulaştırmayı hem İstanbul'un kentleşmesi hem de farklı coğrafyalardaki soylulaştırma örnekleri üzerinden Birleşmeler Kuramıyla incelemiştir. Küresel Kuzey'in ve Güney'in özelliklerini yansıtabilen İstanbul'un tarihi Cihangir mahallesinde yeniden üretilebilen soylulaştırmanın bir süreç olduğu ve oluşlarla şekillendiğini gösterilmiştir. Bugün ölçek ya da kademe üzerinden okunan kentte algıladığımız her şey, güç ilişkileriyle oluşan yapılar ve alanlar, yatay ilişkilerle şekillenecektir. Süreç içinde doğal ve yapay bütün parçalar farklı biçimlerde bir araya gelerek, yeniden kurgulanıp ve yeni formlar oluşturacaktır.

\section{Değerlendirme}

Günümüzden bakınca geleceğin kentlerinin bugünün kentlerinden farklı olacağı ve kentsel olaylara, durumlara veya sorunlara karşı geçmiş deneyimlerimizin yol göstermede yetersiz kalacağı açıktır. Bu noktada kentlere ilişkin araştırmaların önemi artmaktadır. Yukarıda kısaca özetlemeye çalıştığımız gibi son dönemde zengin akademik tartışmalar ortaya çıkmıştır. 

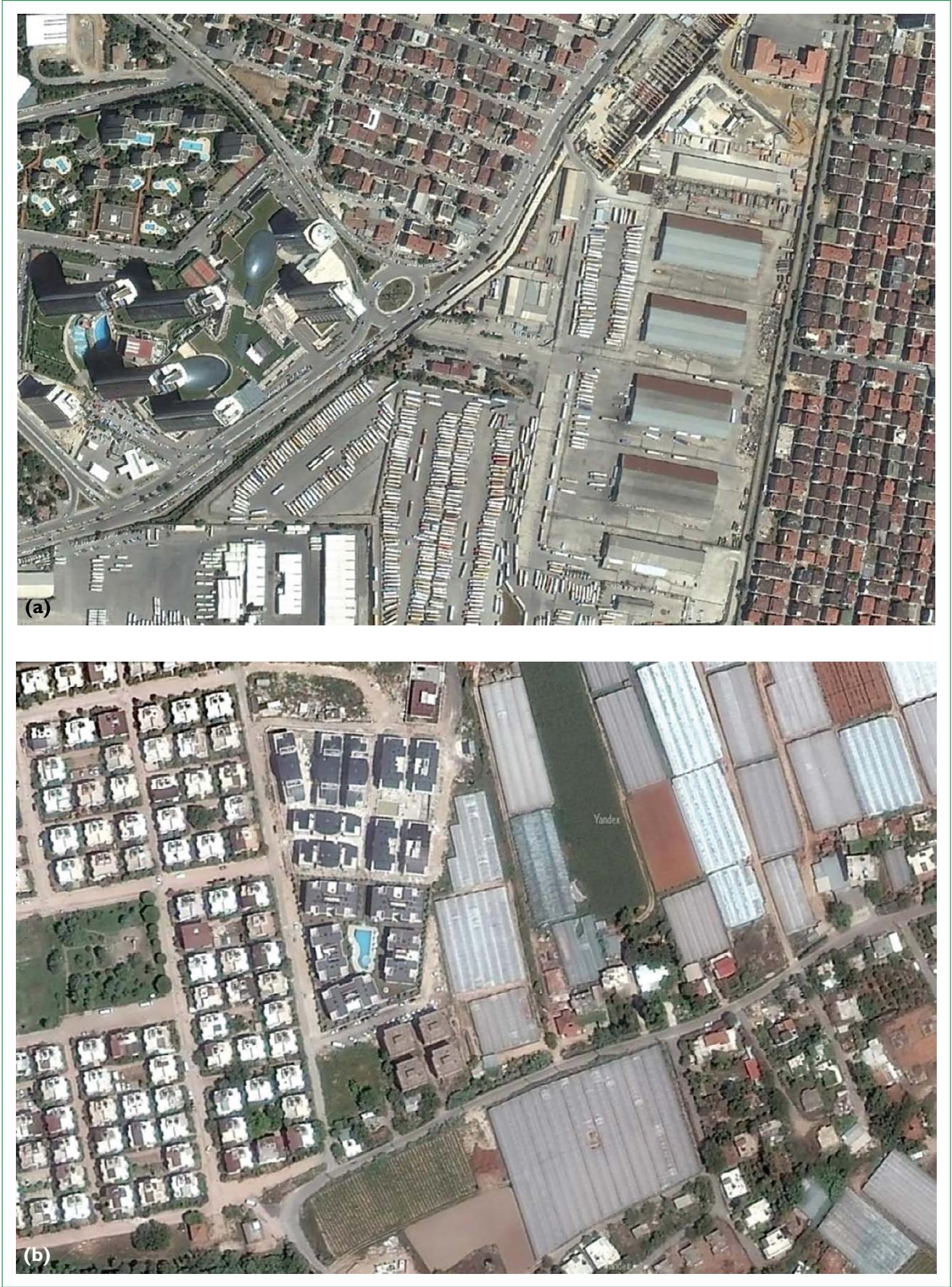

Şekil 3. (a) Kentsel parçaların birleşimi (Ataşehir, İstanbul). (b) Kentsel ve kırsal parçaların birleşimi (Muratpaşa, Antalya) (Yandex, 2019).

Ancak kent 'tuhaf bir sorundur. Belirsiz, doğrusal olmayan ve karmaşık yapısı nedeniyle kentin tanımlanabilir bir başlangıcı, sonu veya çözümü yoktur (lossifova vd. 2018). Kente ilişkin herhangi bir olay, durum veya sorun, bugüne kadar tanımladığımızdan farklı olarak yeni bir form ile ortaya çıkmaktadır. Bu geçmişten tamamen bağımsız da değildir. Bugün tutarlı bir bütünü oluşturan parçalar gelecekte birbirinden ayrilacak ve karşımıza yeni bir olay, durum veya sorun olarak çıkacaktır.
Bu karmaşık yapı, kentleri sürekli çalışmamızı ve araştırmamızı gerekli kılmaktadır. Bu nedenle üzerinde uzlaştığımız bir tanımın veya tamamen ikna olduğumuz bir kentsel kuramın veya yaklaşımın olmamasını da doğal karşılamak gerekiyor.

Kentleşmeyi merkezine alan üç yeni yaklaşım da kentlere, kentleşmeye ve kentselliğe ilişkin bugüne kadar bilinegelen doğrusalıkların, hiyerarşilerin ve sınıflandırmaların eleştirisi 
üzerinden geliştirilmiştir. Her ne kadar üçü de var olan kuramları değersizleştirdiği veya tartışılagelen kentsel sorunları indirgediği için eleştirilse de Gezegensel Kentleşme, kent-kır ikilemini, Postkolonyal Kentleşme, Küresel Kuzey-Güney veya Batı-Doğu ikilemini ve Birleşmeler Kentleşmesi de geçmişipotansiyeli veya gerçekleşeni-olasılığı sorgulamaktadır. Hiç biri diğerinden keskin sınırlarla ayrılmadığı için bu üç yeni kuramın aralarındaki kesişim alanları da araştırılmaktadır. De Roo (2010) nesnellik ve maksimizasyon temelli teknik akılcılıkla (technical rationality) süreç ve optimizasyon temelli iletişimsel akılcılığın (communicative rationality) arasındaki "bulanık ortayı" işaret ederek, gerçek planlama sorunlarının çözümlerini orada bulacağımızı söylemiştir. Daha ileriye gidersek, Thrift (2008), sosyal bilimlerin her şeyi açıklama, tahmin etme, kontrol etme arzusunu bir kenara bırakması gerektiğini; ve bir şeyleri rapor etmekten ziyade parçalamayı, sarsmayı, sınırları zorlayarak yenilenmeyi hedeflemesi gerektiğini vurgulamışır.

\section{KAYNAKLAR}

Amin, A. \& Graham, S. (1997). The Ordinary City. Transactions of the Institute of British Geographers, 22(4): 411-29.

Angelo, H. \& Wachsmuth, D. (2014). Urbanizing urban political ecology: A critique of methodological cityism. International Journal of Urban and Regional Research, 39(1), 16-27.

Arslan Avar, A. (2009). Lefebvre in Üçlü Algılanan, Tasarlanan, Yaşanan Mekan- Diyalektiği, Dosya 17, Ankara: TMMOB Mimarlar Odası Ankara Şubesi Yayını, s. 7-16.

Batty, M. \& Longley P. (1994). Fractal Cities: A Geometry of Form and Function. San Diego: Academic Press.

Benenson, I. \& Torrens, P.M. (2004). Geosimulation: Automata-based Modeling of Urban Phenomena. Chichester: John Wiley \& Sons.

BİB, Bayındırlık ve İskan Bakanlığı (2009). Kentleşme Şurası Komisyon Raporları. Ankara: Bayındırlıkve İskan Bakanlı̆̆ı.

Brenner, N. \& Schmid, C. (2014). The 'Urban Age' in Question. International Journal of Urban and Regional Research, 38(3), 731-755.

Brenner, N. (Ed.) (2014). Implosions/Explosions: Towards a Study of Planetary Urbanization. Berlin: Jovis.

Castells, M. (1977). The Urban Question. London: Edward Arnold.

Castells, M. (1978). City, Class and Power. London: Macmillan.

Cochrane, A. (2018). Here, There and Everywhere: Rethinking the Urban of Urban Politics. Kevin Ward, Andrew E.G. Jonas, Byron Miller \& David Wilson (Eds.), The Routledge Handbook on Spaces of Urban Politics içinde (s. 14-25). Oxon: Routledge.

Comaroff, J. \& Comaroff, J.L. (2012). Theory from the South: How EuroAmerica is Evolving toward Africa. Boulder, CO: Paradigm.

Davis, K. (1955). The Origin and Growth of Urbanization in the World. American Journal of Sociology, 60(5):429-437.

De Roo, G. (2010). Planning and Complexity: An Introduction. Gert de Roo $\&$ Elisabete A. Silva (Eds.), A Planner's Encounter with Complexity. Surrey: Ashgate Publishing, Surrey.

DeLanda, M. (2002). Intensive Science and Virtual Philosophy. London: Continuum.

DeLanda, M. (2006). A New Philosophy of Society: Assemblage Theory and Social Complexity. London: Continuum.

Deleuze, G. \& Guattari, F. (1987 [1980]). A Thousand Plateaus: Capitalism and Schizophrenia. Çeviri: B. Massumi, Athlone Press, London.

Ernstson, H. (2014). Pluralizing or Provicializing Urban Political Ecology? [In a World of Cities]. Situated Ecologies. Erişim: http://www.situatedecologies.net/archives/936.

Eyrice Tepeciklioğlu, E. (2013). Postkolonyal Kuram Uluslararası İlişkiler Disiplinini Dekolonize Etmek. Ege Stratejik Araştırmalar Dergisi, 4(2), 91.

Farías, I. (2011). The politics of urban assemblages. City, 15(3-4), 365-374.

Harvey, D. (1973). Social Justice and The City. Johns Hopkins Studies in Urban Affairs, Baltimore, MD: Johns Hopkins University Press.

Harvey, D. (1985). Consciousness and the Urban Experience: Studies in the History and Theory of Capitalist Urbanization. Baltimore: Johns Hopkins University.

Harvey, D. (1989). The Urban Experience. Baltimore, Maryland: John Hopkins University Press.

Harvey, D. (1996). Cities or Urbanization? City, 1(1-2), 38-61.

Iossifova, D., Gasparatos, A. \& Doll, C.N.H. (Eds.) (2018). Defining the Urban. Oxon: Routlegde.

Jacobs, J. (1961). The Death and Life of Great American Cities: The Failure of Town Planning. New York: Random House/Harmondsworth: Penguin.

Jayne, M. \& Ward, K. (Eds.) (2017). Urban Theory New Critical Perspectives. Oxon: Routledge.

Jonas, A., Miller, B., Ward, K. \& Wilson, D. (2018). Spaces of Urban Politics. Kevin Ward, Andrew E.G. Jonas, Byron Miller \& David Wilson (Eds.), 
The Routledge Handbook on Spaces of Urban Politics içinde (s. 1-10). Oxon: Routledge.

Latour, B. (2005). Re-assembling the Social: An Introduction to Actor Network-Theory. Oxford: Oxford University Press.

Lefebvre, H. (1991 [1974]). The Production of Space. Translated by Donald Nicholson-Smith. Cambridge: Blackwell.

Lefebvre, H. (2003 [1970]). The Urban Revolution. Minneapolis: Minnesota University Press.

Marx, K. (1976). Capital: A Critique of Political Economy, Vol. 1. Giriş: E. Mandel, Çeviri: B. Fowkes. Harmondsworth, NY: Penguin Books.

McFarlane, C. (2011). The city as assemblage: Dwelling and urban space. Environment and Planning D, 29(4), 649-671.

Merrifield, A. (2013). The Urban Question under Planetary Urbanization. International Journal of Urban and Regional Research, 37(3), 910.

Miller, B. \& Jonas, A. (2018). Spaces of The Environment and Nature. Kevin Ward, Andrew E.G. Jonas, Byron Miller \& David Wilson (Eds.), The Routledge Handbook on Spaces of Urban Politics içinde (s. 107-109). Oxon: Routledge.

Mumford, L. (1938). The Culture of Cities. New York City: Harcourt, Brace and Company.

Portugali, J. (2000). Self-Organisation and the City. Heidelberg: Springer.

Robinson, J. \& Roy, A. (2016). Global Urbanisms and the Nature of Urban Theory. International Journal of Urban and Regional Research, 40(1), $181-186$

Robinson, J. (2006). Ordinary Cities: Between Modernity and Development. London: Routledge.

Roy, A. (2005). Urban Informality: Toward an Epistemology of Planning. Journal of the American Planning Association, 71: 147-158.

Roy, A. (2009). The 21st-Century Metropolis: New Geographies of Theory. Regional Studies, 43, 819-830.

Roy, A. (2016). Who's Afraid of Postcolonial Theory? International Journal of Urban and Regional Research, 40(1), 2000-2009.

Said, E.W. (1978). Orientalism. New York: Pantheon.

Sancar, C. (2017). Urbanization in Turkey in Terms of Lobalization and Environmental Problems. Halil İbrahim Aydın, Magdalena Ziolo, Aniela Bălăcescu (Eds.), Economic Development: Global and Regional Studies içinde (s. 263-285). London: Ijopec Publication.

Schlichtman, J.J. (2018). Sociology: The Sociological 'Urban'. Deljana Iossifova, Christopher N.H. Doll, Alexandros Gasparatos (Eds.), Defining the Urban: Interdisciplinary and Professional Perspectives içinde (s. 11-26). Oxon: Routlegde.

Schmid, C. (2008). Henri Lefebvre's Theory of the Production of Space: Towards a Three- Dimensional Dialectic. Kanishka Goonewardena, Stefan Kipfer, Richard Milgrom, Christian Schmid (Eds.), Space, Difference, Everyday Life: Reading Henri Lefebvre içinde (s.27-45). London: Routledge.

Scott, A. \& Storper, M. (2015). The Nature of Cities: The Scope and Limits of Urban Theory. International Journal of Urban and Regional Research, 39(1), 1-15.

Shin, H.B. (2018). Geography: Rethinkinf the 'Urban' and 'Urbanization'. Deljana Iossifova, Christopher N.H. Doll, Alexandros Gasparatos (Eds.), Defining the Urban: Interdisciplinary and Professional Perspectives içinde (s. 27-39). Oxon: Routlegde.

Silva, A. \& Clarke, C. (2005). Complexity, Emergence and Cellular Urban Models: Lessons Learned from Applying Sleuth to Two Portuguese Metropolitan Areas. European Planning Studies, 13(1): 93-116.

Storper, M. \& Scott, A. (2016). Current Debates in Urban Theory: A Critical Assessment. Urban Studies, 53(6), 1117.

Thrift, N. (2008). Non-Representational Theory: Space, Politics, Affect. London: Routledge.

Tönnies, F. (1957). Community \& Society (Gemeinschaft und Gesellschaft). Çeviri: C.P., Loomis, East Lansing, MI: Michigan State University Press.
UN (2016). HABITAT III New Urban Agenda. United Nations Conference on Housing and Sustainable Urban Development, Quito.

UN (2018). Revision of World Urbanization Prospects. Erişim: https:// www.un.org/development/desa/publications/2018-revision-of-worldurbanization-prospects.html (09.07.2019).

Walker, R. (2015). Building a Better Theory of the Urban: A Response to 'Towards a New Epistemology of the Urban?' City, 19(2-3): 183-191.

Weber, A. (1929). Theory of the Location of Industries. Chicago: University of Chicago Press.

Weber, M. (1958). The City. Glencoe, IL: Free Press.

Wezemael, J.V. (2010). Urban Governance and Social Complexity. Gert de Roo \& Elisabete A. Silva (Eds.), A Planner's Encounter with Complexity. Surrey: Ashgate Publishing.

Wirth, L. (1938). Urbanism as a Way of Life. American Journal of Sociology, 44, 5-8.

Yetişkul, E. \& Demirel, S (2017). Assembling Gentrification in Istanbul: The Cihangir Neighbourhood of Beyoğlu. Urban Studies, 55(15): 33363352.

Yetişkul, E. (2017). Karmașı Kentler ve Planlamada Karmaşıklık. Planlama, 27 (1), 7-15.

Young, R.J.C. (2003). Postcolonialism: A Very Short Introduction. Oxford: Oxford University Press.

Zimmer, A., Cornea, N. \& Veron, R. (2018). Urban Political Ecology: Landscapes of Power. Deljana Iossifova, Christopher N.H. Doll, Alexandros Gasparatos (Eds.), Defining the Urban: Interdisciplinary and Professional Perspectives içinde (s. 212-222). Oxon: Routlegde. 